\title{
The delivery of prevention programmes for cardiovascular disease and chronic obstructive pulmonary disease in Lodz by primary care physicians
}

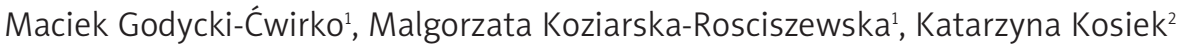

1Department of Family and Community Medicine, Chair of Clinical Sciences, Faculty of Biomedical Sciences and Postgraduate Education, Medical University of Lodz, Lodz, Poland

2Family Medicine Clinic, Lodz, Poland

Submitted: 12 May 2009

Accepted: 11 September 2009

Arch Med Sci 2010; 6, 2: 208-213

DOI: 10.5114/aoms.2010.13897

Copyright @ 2010 Termedia \& Banach

\begin{abstract}
Introduction: In Poland, the National Health Fund (NHF) has contracted preventative interventions in primary health care (PHC) delivered by family physicians, internists, paediatricians and other physicians. The aim of the study was determining whether there is a correlation between PHC physicians' specialisation and the rate of interventions delivered for the prevention of cardiovascular disease (CVD) and chronic obstructive pulmonary disease (COPD). Material and methods: A retrospective observational study of the NHF 2005 data related to the delivery of prevention programmes using Spearman's rank correlation coefficient (rho).

Results: Out of 133 PHC providers in Lodz, 25 participated in the cardiovascular disease (CVD) prevention programme, 22 in the chronic obstructive pulmonary disease (COPD) prevention programme at a basic level, and 20 at an extended level (with contract completion rates respectively of 55.2, 47.8 and 51.5\%). When all three prevention programmes were analysed together, the correlation between the rate of preventative interventions by physicians with a particular specialisation and the contract completion rate was positive ( $r h o>0$ ) only for family physicians. Conclusions: Participation of primary health care providers in preventative programmes and the rates of their delivery of interventions were low despite additional funding. The correlation between the proportion of physicians with a particular specialisation, involved in CVD and COPD prevention interventions delivery, and the rate of the programme accomplishment was the strongest for family physicians.
\end{abstract}

Key words: prevention, cardiovascular disease, chronic obstructive pulmonary disease, family physician, primary health care.

\section{Introduction}

Data concerning the overall prevalence and morbidity of cardiovascular disease (CVD) in Poland are scarce. An estimation based on the Polish Register of Acute Coronary Syndromes showed 140000 cases per year with early mortality rates of $7 \%$ for ST-segment elevation myocardial infarction and 5\% for non-ST-segment elevation myocardial infarction [1, 2]. The prevalence of hypertension within the NATPOL III PLUS study of adults in Poland, with measurements in the clinic setting, was 29\% [3]. The prevalence might be different if diagnoses were validated by ambulatory blood pressure measurements [4]. The estimated prevalence of chronic heart failure in Poland exceeds $2.5 \%$, with the incidence increasing
Corresponding author: Maciek Godycki-Ćwirko, PhD Department of Family and Community Medicine Medical University of Lodz 20 Kopcinskiego Str. 90-153 Lodz, Poland Phone: +48 (0) 426795546 Fax: + 48 (0) 426786041 E-mail: maciekgc@uni.lodz.pl 
with age: $0.3 \%$ for males and $0.2 \%$ for females 50 59 years old; 2.7 and $2.2 \%$ respectively for $70-80$ years old. Mortality for the whole population of patients with heart failure was about $10 \%$ per year [5]. The estimated prevalence of chronic obstructive pulmonary disease (COPD) in Poland exceeded 9.3\%, with $0.7 \%$ mortality rate per year [6-9].

The health care system in Poland is based on compulsory health insurance with near universal coverage of the population, managed by the National Health Fund (NHF), an independent body which contracts services through competitive tendering. Financing the prevention of diseases is part of the responsibilities of the NHF, regulated by the Health Care Services Financed with Public Funds Act of 27 August 2004. Preventive interventions are part of annually-updated prevention programmes delivered in primary health care with payments based on fee for service.

In 2005, the programmes focused on CVD and COPD. In the Lodz region, with a population of 765,777 inhabitants, the NHF signed contracts for 53,996 CVD prevention interventions, for 65,400 COPD prevention interventions at the basic level, and for 13,776 COPD prevention interventions at the extended level. The contracts were signed directly with primary care physicians or with Health Care Enterprises which employed physicians.

The aim of the CVD prevention programme was to reduce the incidence and mortality of CVD by $20 \%$ by the early identification and reduction of risk factors. Specific objectives were to increase identification and the effectiveness of the treatment of CVD, identification of people at risk and promotion of a healthy lifestyle. The CVD prevention programme was targeted towards people 35-55 years old with no previous diagnosis of CVD.

The aim of the COPD prevention programme was to reduce the incidence and disability related to COPD by complex educational, diagnostic and therapeutic interventions in people at risk. The specific objectives were promotion of COPD awareness, screening and early identification of COPD, appropriate referrals, anti-smoking education, flu vaccination and reduction of hospital referrals. The COPD programme was targeted towards people 40-65 years old, current or past tobacco smokers with no previous diagnosis of COPD.

The aim of this study was to determine whether there was a correlation between the primary health care physicians' specialty and the rate of the delivered interventions contracted by the NHF as part of CVD and COPD prevention programmes in Lodz.

\section{Material and methods}

In this retrospective observational study, data from 2005 were analysed. The source of information was National Health Fund data related to the accomplishment of contracts signed for the CVD prevention programme and the COPD prevention programmes at the basic and extended levels. The data included the numbers of interventions contracted and delivered by all primary care providers who signed the contracts, and the number of physicians who performed prevention interventions with their medical specialisations. Since the data were used by the NHF as the basis for payment, their quality was checked by different departments of the NHF. There were no data missing. Researchers had access to both the electronic and paper-based data sets.

The rates of delivery of preventative interventions within the CVD and COPD prevention programmes by physicians with different specialities (internists, paediatricians, family physicians and physicians with or without any other speciality) were analysed. The analysis was performed using Spearman's rank correlation coefficient (rho), which estimates the strength of the relationship between two parameters and its tendency. The "+" symbol means that when the value of one parameter grows, the other parameter's value grows as well; the "-" symbol means that when the value of one parameter increases, the value of the other parameter diminishes. The value of Spearman's rank correlation coefficient ranges from -1 to 1 . The closer to " 0 " the absolute value of the coefficient, the weaker the correlation; conversely, the closer to " 1 " the absolute value of the coefficient, the stronger the correlation.

Since the data were not identifiable, ethical committee approval was not necessary.

\section{Results}

Out of 133 primary health care providers in Lodz, only 25 signed contracts for the CVD prevention programme - 22 for the COPD prevention programme at the basic level and 20 at the extended level.

Seventy-nine family physicians $(30.74 \%$ of all primary care physicians, $95 \%$ Cl 25.10-36.38), 81 specialists in internal medicine $(31.52 \%, 95 \% \mathrm{Cl}$ 25.84-37.18), 40 paediatricians (15.56\%, 95\% Cl 11.1319.99), and 57 physicians with or without another specialisation $(22.18 \%, 95 \% \mathrm{Cl} 17.10-27.26)$ were involved in the CVD prevention programme delivery. In total, there were 257 primary care physicians involved (100.00\%), including 162 (63\%) females.

In the COPD prevention programme delivery at the basic level 54 family physicians $(23.08 \%$ of all primary care physicians, $95 \% \mathrm{Cl} 17.68-28.48)$, 104 internal medicine specialists $(44.44 \%, 95 \% \mathrm{Cl}$ $38.07-50.81), 54$ paediatricians $(23.08 \%, 95 \% \mathrm{Cl}$ 17.68-28.48), and 22 physicians with or without another specialisation $(9.40 \%, 95 \% \mathrm{Cl} 5.66-13.14)$ were involved. In total, there were 234 primary care 
Table I. Accomplishment rates of CVD and COPD prevention programmes in Lodz

\begin{tabular}{|c|c|c|c|c|c|c|c|}
\hline $\begin{array}{l}\text { Prevention } \\
\text { programme }\end{array}$ & $\begin{array}{l}\text { Number } \\
\text { of health } \\
\text { care } \\
\text { providers }\end{array}$ & $\begin{array}{c}\text { Total } \\
\text { number of } \\
\text { interventions }\end{array}$ & $\begin{array}{l}\text { Minimum } \\
\text { number of } \\
\text { interventions } \\
\text { contracted }\end{array}$ & $\begin{array}{l}\text { Maximum } \\
\text { number of } \\
\text { interventions } \\
\text { contracted }\end{array}$ & $\begin{array}{c}\text { Mean } \\
\text { number of } \\
\text { interventions } \\
\text { contracted }\end{array}$ & $\begin{array}{l}\text { Standard } \\
\text { deviation }\end{array}$ & $\begin{array}{c}\text { Contract } \\
\text { accompli- } \\
\text { shment } \\
\text { rate (\%) }\end{array}$ \\
\hline $\begin{array}{l}\text { CVD } \\
\text { interventions } \\
\text { contracted }\end{array}$ & 25 & 53996.0 & 300.0 & 12000.0 & $\begin{array}{l}2159.8 \\
(95 \% \mathrm{Cl} \\
1144.5- \\
3175.2)\end{array}$ & 2459.8 & $\begin{array}{c}55.2 \\
(95 \% \mathrm{Cl} \\
35.7-74.7)\end{array}$ \\
\hline $\begin{array}{l}\text { CVD } \\
\text { interventions } \\
\text { delivered }\end{array}$ & 25 & 29796.0 & 0.0 & 6552.0 & $\begin{array}{c}1191.8 \\
(95 \% \mathrm{Cl} \\
585.1- \\
1798.6)\end{array}$ & 1470.0 & \\
\hline $\begin{array}{l}\text { COPD } \\
\text { - basic level } \\
\text { interventions } \\
\text { contracted }\end{array}$ & 22 & 65400.0 & 600.0 & 10000.0 & $\begin{array}{l}2972.7 \\
(95 \% \mathrm{Cl} \\
1921.6- \\
4023.8)\end{array}$ & 2370.7 & $\begin{array}{c}47.8 \\
(95 \% \mathrm{Cl} \\
26.7-68.7)\end{array}$ \\
\hline $\begin{array}{l}\text { COPD } \\
\text { - basic level } \\
\text { interventions } \\
\text { delivered }\end{array}$ & 22 & 31244.0 & 0.0 & 9268.0 & $\begin{array}{c}1420.2 \\
(95 \% \mathrm{Cl} \\
550.8- \\
2289.6)\end{array}$ & 1960.9 & \\
\hline $\begin{array}{l}\text { COPD } \\
\text { - extended } \\
\text { level } \\
\text { interventions } \\
\text { contracted }\end{array}$ & 20 & 13776.0 & 200.0 & 2236.0 & $\begin{array}{c}688.8 \\
(95 \% \mathrm{Cl} \\
413.7- \\
963.9)\end{array}$ & 587.8 & $\begin{array}{c}51.5 \\
(95 \% \mathrm{Cl} \\
29.6-73.4)\end{array}$ \\
\hline $\begin{array}{l}\text { COPD } \\
\text { - extended } \\
\text { level } \\
\text { interventions } \\
\text { delivered }\end{array}$ & 20 & 7096.0 & 0.0 & 2312.0 & $\begin{array}{c}354.8 \\
(95 \% \mathrm{Cl} \\
92.4-617.2)\end{array}$ & 560.7 & \\
\hline
\end{tabular}

Table II. Numbers of physicians who delivered CVD and COPD prevention interventions in Lodz by specialisation

\begin{tabular}{|lccc|}
\hline $\begin{array}{l}\text { Specialisation } \\
\text { of physicians }\end{array}$ & $\begin{array}{c}\text { CVD prevention } \\
\text { programme }\end{array}$ & $\begin{array}{c}\text { COPD prevention } \\
\text { programme basic level }\end{array}$ & $\begin{array}{c}\text { COPD prevention } \\
\text { programme extended level }\end{array}$ \\
\hline Family medicine & $79(30.74 \%, 95 \% \mathrm{Cl}$ & $54(23.08 \%, 95 \% \mathrm{Cl}$ & $54(23.28 \%, 95 \% \mathrm{Cl}$ \\
& $25.10-36.38)$ & $17.68-28.48)$ & $17.84-28.72)$ \\
\hline Internal medicine & $81(31.52 \%, 95 \% \mathrm{Cl}$ & $104(44.44 \%, 95 \% \mathrm{Cl}$ & $102(43.97 \%, 95 \% \mathrm{Cl}$ \\
& $25.84-37.18)$ & $38.07-50.81)$ & $37.58-50.36)$ \\
\hline Paediatrics & $40(15.56 \%, 95 \% \mathrm{Cl}$ & $54(23.08 \%, 95 \% \mathrm{Cl}$ & $54(23.28 \%, 95 \% \mathrm{Cl}$ \\
& $11.13-19.99)$ & $17.68-28.48)$ & $17.84-28.72)$ \\
\hline Other & $57(22.18 \%, 95 \% \mathrm{Cl}$ & $22(9.40 \%, 95 \% \mathrm{Cl}$ & $22(9.48 \%, 95 \% \mathrm{Cl}$ \\
& $17.10-27.26)$ & $5.66-13.14)$ & $5.71-13.25)$ \\
\hline Physicians (total) & $257(100.00 \%)$ & $234(100.00 \%)$ & $232(100.00 \%)$ \\
\hline
\end{tabular}

physicians involved (100.00\%), including 147 (63\%) females. In the programme delivery at the extended level 54 family physicians $(23.28 \%$ of all primary care physicians, $95 \% \mathrm{Cl} 17.84-28.72), 102$ specialists in internal medicine $(43.97 \%, 95 \% \mathrm{Cl} 37.58-50.36)$, 54 paediatricians $(23.28 \%, 95 \% \mathrm{Cl} 17.84-28.72)$, and 22 physicians with or without another specialisation (9.48\%, 95\% Cl 5.71-13.25) were involved. In total 232 primary care physicians $(100.00 \%)$, including 142 females (61\%), were involved.
Accomplishment rates of the CVD and COPD prevention programme in Lodz and the numbers of physicians involved in CVD and COPD prevention programmes in Lodz by specialisation are presented in Tables I and II.

The relationship expressed by Spearman's rank correlation coefficient between the proportion of physicians with a particular specialisation who delivered the CVD and COPD prevention interventions and the rate of contract accomplishment 
varied. For the CVD prevention programme, the correlation was strong and positive only for family physicians ( $r$ o $=0.190$ ), while it was weak for internal medicine specialists and other physicians (rho $=0.001$ and rho $=0.018$, respectively) and negative for paediatricians ( $r h o=-0.085$ ). For the COPD prevention programme on the basic level, the correlation was strong and positive again for family physicians ( $r$ ho $=0.283$ ), while it was quite strongly negative for internal medicine specialists and other physicians ( $r$ o $=-0.249$ and rho $=-0.184$, respectively), although it was weakly positive for paediatricians (rho $=0.071$ ). For the COPD prevention programme at the advanced level, the correlation was strong and positive for family physicians ( $r h o=0.262$ ), slightly positive for internal medicine specialists (rho $=0.001)$ and quite strongly negative for other physicians and paediatricians ( rho $=-0.461$ and rho $=-0.260$, respectively) . Although most of these results did not reach statistical significance, the observed tendency was nevertheless interesting.

There was a positive correlation in all of the three prevention programmes separately (rho $>0$ ) and a significantly positive correlation for all programmes together only for family physicians $(p<0.005)$ (Table III).

\section{Discussion}

In some countries, such as Poland, primary care is provided by family physicians, internal medicine specialists, paediatricians and physicians with or without another medical speciality. Because these physicians are also involved in prevention programmes, it has become essential to ask whether the primary care physician's specialisation (vocational training), particularly a specialisation in family medicine, is important in the delivery of these programmes.

The results of the study revealed differences between the specialisations. While the involvement of family physicians correlated well with better programme delivery, the correlation for physicians with other specialisations or without specialisation was quite different, which made the result even more noteworthy.

A search of the Medline database showed papers reporting a correlation between the delivery of prevention programmes in primary care and preventive intervention, education strategies, involvement in the community, a focus on population, and remote location [10-14]. However, reviewing medical and public health journals the authors found no previous papers on the correlation between a primary health care physician's speciality and the delivery of prevention programmes. One paper recommended the need for an economic analysis of prevention programmes [15].

The overall body of evidence showing the effectiveness of preventive activities is growing [16]. These activities should be performed in a primary care setting. Primary care physicians see two thirds of patients from their lists one or more times each year and $90 \%$ at least once in 5 years [17], so they are in an excellent position within the health care system to administer preventive care in an opportunistic manner. However, they are confronted with many difficulties in its implementation, listing such factors as: work load, lack of time, lack of reimbursement, discrepancies in guidelines, patients' doubts about effectiveness, lack of clarity about which professional in primary care is responsible for prevention, as well as insufficient personal training in prevention and health promotion [18]. All of these difficulties create barriers, and as a consequence some studies have shown low reported rates of preventive interventions being implemented [19].

It appears that no studies have examined the possible role of family physicians in the delivery of prevention programmes, including CVD and COPD prevention programmes.

In addition, other factors related to various levels of delivery of preventive care are unclear. Brotons

Table III. Relationship between the proportion of physicians who delivered CVD and COPD prevention interventions and the rate of contract completion

\begin{tabular}{|lcccc|}
\hline $\begin{array}{l}\text { Prevention } \\
\text { programme }\end{array}$ & $\begin{array}{c}\text { Spearman's rank } \\
\text { correlation } \\
\text { coefficient for } \\
\text { family physicians } \\
\text { (rho) }\end{array}$ & $\begin{array}{c}\text { Spearman's rank } \\
\text { correlation } \\
\text { coefficient for } \\
\text { internists } \\
\text { (rho) }\end{array}$ & $\begin{array}{c}\text { Spearman's rank } \\
\text { correlation } \\
\text { coefficient for } \\
\text { paediatricians } \\
\text { (rho) }\end{array}$ & $\begin{array}{c}\text { Spearman's rank } \\
\text { correlation } \\
\text { coefficient for } \\
\text { other physicians } \\
\text { (rho) }\end{array}$ \\
\hline CVD & $0.190(p>0.05)$ & $0.001(p>0.05)$ & $-0.085(p>0.05)$ & $0.018(p>0.05)$ \\
\hline COPD basic level & $0.283(p>0.05)$ & $-0.249(p>0.05)$ & $0.071(p>0.05)$ & $-0.184(p>0.05)$ \\
\hline COPD extended level & $0.262(p>0.05)$ & $0.002(p>0.05)$ & $-0.260(p>0.05)$ & $-0.461(p<0.05)$ \\
\hline $\begin{array}{l}\text { All programmes } \\
\text { combined* }\end{array}$ & $0.258(p<0.03)$ & $-0.109(p>0.05)$ & $-0.107(p>0.05)$ & $-0.234(p>0.05)$ \\
\hline
\end{tabular}

${ }^{*}$ Correlation for three programmes combined (CVD; COPD, basic level; COPD, extended) 
et al. described an unequal level of performance depending on the preventive procedure and on the targeted population [20]. Some studies have concentrated on attitudes to and involvement in health promotion and lifestyle counselling [21], and the perception of family physicians' role in modifying behaviour [22].

The reasons for the study results may be found in available incentives. There was no financial incentive specific to any of the groups of physicians since there was one universal payment for intervention regardless of the specialisation of the providers. The type of intervention did not seem to be important since the trend was the same for all the programmes and their combinations. Therefore it may be a feature of the individual physician, related to his/her vocational training and performance.

Family physicians provide continuous, general, comprehensive, family and community oriented health care $[23,24]$. As a result of their training, as well as their family and community orientation, they may also have a stronger public health orientation than other medical specialists. They may be more efficient than other specialists in leading the incorporation of health goals within the broader public agenda, collaboration with government, encouragement of coalitions, integrated approaches and commitment to evaluation of processes and outcomes in local communities, factors which proved to lead to success in other programmes [25].

Family physicians believe they should advise on prevention and health promotion issues [18, 26], although these tasks should be a part of more comprehensive community-based activities and national policy [27]. The results of this study supported these beliefs and present an argument to develop policies to strengthen the role of the family physician as a cornerstone of a public health oriented health care system.

The results also suggest the need for specific educational programmes directed at physicians with different specialisations and for specific incentives for different physicians participating in preventive programmes.

The strength of this study was the inclusion of all physicians involved in CVD and COPD prevention programmes. They also would not have been aware of the researchers' interest in exploring differences in the role of specialisation. A limitation could be the involvement of urban physicians only, although one can assume that in a public health care system with undifferentiated capitation payments a nonurban setting would not alter the results. Another limitation could be a bias as a result of focusing only on two prevention programmes. Again, one could argue that these programmes were the most appropriate to evaluate physicians' attitude towards prevention, considering the potential health gain related to the prevention in the case of these two particular diseases.

Further research on the correlation between the specialty of primary care physicians and the rate of delivery of care they provide is needed.

In conclusions:

- participation of primary health care providers in preventative programmes and the rates of their delivery of interventions were low despite additional funding;

- the correlation between the proportion of physicians with a particular specialisation, involved in CVD and COPD prevention interventions delivery, and the rate of programme accomplishment was the strongest for family physicians;

- further assessment of the correlation between the specialisation of primary care physicians and the care they provide may facilitate decisions related to vocational training for primary health care and the implementation of preventative programmes.

\section{Acknowledgments}

The authors wish to thank the President of Lodz for the grant supporting the research performed, the employees of the National Health Fund in Lodz for providing the data and Professor Nigel Mathers for reviewing the manuscript.

\section{References}

1. Polonski L, Gasior M, Gierlotka M, Zembala M. Epidemiology, treatment and prognosis of acute coronary syndromes at Silesia - PL-ACS register [Polish]. Kardiol Pol 2005; 62: 122-7.

2. Wierzbowska-Drabik K, Kasprzak JD. Management on non-ST-segment elevation acute coronary syndromes. Current ECS recommendations [Polish]. Lek Rodz 2008; 2: $148-61$.

3. Zdrojewski T, Wyrzykowski B, Szczech R et al. Epidemiology and prevention of arterial hypertension in Poland [Polish]. Nadcisnienie tetnicze 2005; 14 Suppl 2: 10-16.

4. Sethi A, Arora RR. Ambulatory blood pressure as a predictor of cardiovascular risk. Arch Med Sci 2009; 5: 3-9.

5. National Program for Prevention and Treatment of Cardiovascular Disease in 2006-2008 „POLKARD 20062008" [Polish]. http://www.mz.gov.pl/wwwmz/index?mr $=m 241614181 \& m s=416 \& m l=p l \& m i=418 \& m x=0 \& m t=\& m$ $y=153 \& m a=07867$. Accessed Oct 6, 2008.

6. Maciejewski J. Prevelance of COPD in family physician practice. PhD thesis [Polish]. Warsaw, Institute of Tuberculosis and Pulmonary Diseases, 2007.

7. Bednarek M, Plywaczewski R, Górecka D, et al. Early identification of COPD in smoking inhabitants of Warsaw [Polish]. Pneumonol Alergol Pol 2002; 70: 139-47.

8. Niepsuj G, Kozielski J, Niepsuj K, et al. Chronic obstructive pulmonary disease in Zabrze inhabitants [Polish]. Wiad Lek 2002; 55 Suppl 1: 354-9.

9. Polish Respiratory Society. Recommendations of Polish Respiratory Society on identification and treatment of 
chronic obstructive pulmonary disease [Polish]. Pneumonol Alergol Pol 2004; 72 Suppl 1: 6-25.

10. Mittelmark MB, Luepker RV, Jacobs DR, et al. Communitywide prevention of cardiovascular disease education strategies of the Minesota Heart Program. Prev Med 1986; 15: 1-17.

11. Curd P, Pearce K, Schumacher K. Physician roles in improving cardiovascular health: counselling patients and involvement in the community. J Ky Med Assoc 2004; 102: 433-42.

12. Novick LF, Cibula DA, Sutphen SM, Rixey S, Epling JW, Morrow CB. Measuring orientation to population-based prevention. Am J Prev Med 2003; 24 (4 Suppl): 95-101.

13. Hogg W, Lemelin J, Graham ID, et al. Improving prevention in primary care: evaluating the effectiveness of outreach facilitation. Fam Pract 2008; 25: 40-8.

14. Shea S, Basch CE. A review of five major community-based cardiovascular disease prevention programs. Part II: Intervention strategies, evaluation methods, and results. Am J Health Promot 1990; 4: 279-87.

15. Stelmach W, Bryla M. The need of economic evaluation of preventive health programs [Polish]. Pol J Public Health 2001; 111: 194-8.

16. US Preventive Services Task Force. Guide to Clinical Preventive Services. $2^{\text {nd }}$ ed. Baltimore, Md: Williams \& Wilkins 1996.

17. Fraser RC. Setting the Scene. In: Fraser RC (ed.). Clinical method. A general practice approach. $2^{\text {nd }}$ ed. Oxford: Butterworth Heinmann; 1992.

18. Brotons C, Bjorkelund C, Bulc M, et al. Prevention and health promotion in clinical practice: the views of general practitioners in Europe. Prev Med 2005; 40: 595-601.

19. Anderson LM, May DS. Has the use of cervical, breast, and colorectal cancer screening increased in the United States? Am J Public Health 1995; 85: 840-2.

20. Brotons C, Iglesias M, Martín Zurro A, Martín Rabadán M, Gene J. Evaluation of preventive and health promotion activities in 166 primary care practices in Spain. Fam Pract 1996; 13: 144-51.

21. McAvoy B, Kaner EFS, Lock LA, Heather N, Gilvarry E. Our Healthier Nation: are general practitioners willing and able to deliver? A survey of attitudes to and involvement in health promotion and lifestyle counselling. Br J Gen Pract 1999; 49: 187-90.

22. Wechsler H, Levine S, Idelson RJ, Schor EL, Coakley E. The physician's role in health promotion revisited- a survey of primary care practitioners. N Eng J Med 1996; 334: 996-8.

23. World Health Organization Europe. Framework for Professional and Administrative Development of General Practice/Family Medicine in Europe. Copenhagen (Denmark), WHO; 1998.

24. Krol ZJ, Godycki-Cwirko M. Family physician as a coordinator of the patient care [Polish]. Lek Rodz 2006; 4: 384-91.

25. White F, Nanan D. Community health case studies selected from developing and developed countries common principles for moving from evidence to action. Arch Med Sci 2008; 4: 358-63.

26. Jacobsen ET, Rasmussen SR, Christensen M, Engberg M, Lauritzen T. Perspectives on lifestyle intervention: the views of general practitioners who have taken part in a health promotion study. Scand J Public Health 2005; 33: 4-10.

27. Pineiro R, Brotons C, Bulc M, et al. Healthy diet in primary care: views of general practitioners and nurses from Europe. Eur J Clin Nutr 2005; 59 Suppl 1: S77-80. 